\title{
TRANSFORMAÇÕES EM ORGANIZAÇÕES DE FRUTICULTURA IRRIGADA E A DINÂMICA DO COMPROMETIMENTO ORGANIZACIONAL
}

\author{
Fabíola Marinho Costa \\ fabiola@ufrb.edu.br \\ Universidade Federal do Recôncavo da Bahia - Santo Antônio de Jesus, BA / Brasil \\ Antonio Virgílio Bittencourt Bastos \\ virgilio@ufba.br \\ Universidade Federal da Bahia - Salvador, BA / Brasil
}

Recebido em 05/10/2011
Aprovado em 25/02/2013
Disponibilizado em 01/12/2013
Avaliado pelo sistema double blind review
Revista Eletrônica de Administração
Editor: Luís Felipe Nascimento
ISSN 1413-2311 (versão on-line)
Editada pela Escola de Administração da Universidade Federal do Rio Grande do Sul.
Periodicidade: Quadrimestral
Sistema requerido: Adobe Acrobat Reader.

RESUMO

As transformações no mundo do trabalho e suas consequências sobre as relações de trabalho enfatizam a importância de se considerar o comprometimento organizacional como um fenômeno que é construído processualmente e que pode se alterar ao longo do tempo, destacando a pertinência da realização de estudos longitudinais. Nesse sentido, o presente trabalho objetiva avaliar o processo de comprometimento afetivo (CA), de comprometimento de continuação (CC), de percepção de suporte organizacional (PSO) e de intenção de deixar a organização (IDO), associando-os às transformações organizacionais percebidas pelo gestor e trabalhadores. Foram coletados dados em três organizações de fruticultura irrigada de um mesmo grupo econômico do Vale do São Francisco, em quatro momentos, com intervalos de seis meses. Foram aplicados questionários com questões sobre transformações organizacionais percebidas e quatro escalas: CA, CC, PSO e IDO. Nos quatro tempos, participaram 114, 135, 162 e 162 trabalhadores, respectivamente, tendo 46 participado nos quatro tempos. Os participantes foram, em sua maioria, homens, jovens e de baixa escolaridade. Realizaram-se análises descritivas e comparações de médias. Ao longo dos dois anos investigados, os trabalhadores perceberam mudanças na estrutura física, no processo de trabalho, nas chefias, no quadro de funcionários e destacaram o atraso no pagamento dos salários como uma importante mudança. $\mathrm{Na}$ amostra total, observou-se uma redução nas médias de CA e de CC, acompanhadas por uma queda da média de PSO até o tempo 3 e por um aumento de IDO até o tempo 3. A mesma tendência foi observada entre os 46 trabalhadores, tendo ocorrido reduções estatisticamente significativas das médias de PSO entre os tempos 1 e 3 , e entre os tempos 2 e 3, e de CA e de CC entre os tempos 2 e 3. Também foi verificado um aumento estatisticamente significativo de IDO entre os tempos $1 \mathrm{e}$ 3. Os achados contribuem para a compreensão de que os fenômenos organizacionais investigados são construídos processualmente e se alteram ao longo do tempo. Os decréscimos de PSO, CA e CC, e o aumento de IDO podem estar relacionados ao contexto de

REAd | Porto Alegre - Edição 76 - No 3 - setembro/dezembro 2013 - p. 675-708 
Transformações em organizações de fruticultura irrigada e a dinâmica do comprometimento organizacional

mudanças nas organizações, ocorridas ao longo de um período de crise no Vale do São Francisco, e marcadas pela queda nos preços das frutas no mercado externo, pelo aumento de demissões e por reestruturações organizacionais. Conclui-se que há grande relevância em estudos longitudinais que analisem o processo de comprometimento, sendo necessária sua compreensão à luz do contexto organizacional.

Palavras-Chave: Comprometimento Organizacional; Mudanças Organizacionais; Estudo longitudinal; Trabalhadores Agrícolas.

\title{
ORGANIZATIONAL CHANGE AND ORGANIZATIONAL COMMITMENT PROCESS
}

\begin{abstract}
Change in the world of work and its impact on labor relations emphasizes the importance of considering organizational commitment as a process that may change overtime, reinforcing the need for longitudinal studies. The present study seeks to assess the process of affective commitment (AC), continuation commitment (CC), perception of organizational support (POS) and intention to leave the organization in relation to organizational change as perceived by managers and workers. In this sense, data were collected from three companies in four different points in time over a six month period. The organizations belong to the same economic group with activities targeting irrigated fruit culture at the São Francisco ValleyBA. Data was collected, in four different points of time, within three different organizations in the primary sector of the economy, all of them belonging to the same economic group. The samples consisted of 114 workers in time 1, 135 in time 2, 162 in time 3 and 162 in time 4 . A total of 46 workers took part in all four data collection. The participants were mostly young males with low schooling level. The main analysis consisted of descriptive statistics and mean comparisons. Over the years workers perceived changes in the companies' physical structure, in the work process, in leadership, in the workforce and an important trend towards wage's payments delay .A mean reduction in AC, CC and OSP coupled with a mean increase in ILO was observed in time 3 . The same trend was observed among 46 workers, with statistically significant OSP mean reductions between time 1 and 3 , and time 2 and 3 . The same pattern was observed with $\mathrm{AC}$ and $\mathrm{CC}$ between time 2 and 3. On the other hand, a statistically significant increase in ILO mean was observed from time 1 and 3 . The findings contribute to the understanding of organizational commitment as a process that has to be understood over time. The decreases in OSP, AC and CC, and the increases in ILO may be related the organizations change context due to a long price crises that hit the fruit market and was characterized by increases in lay-offs and organizations restructuring during the period under investigation. It can be said that there is great relevance in longitudinal studies analyzing the commitment processes that has to be understood under the light of organizational context.
\end{abstract}

Keywords: Organizational Commitment; Organizational Change; Longitudinal Study; Agricultural Workers.

\section{INTRODUÇÃO}

Considerado um importante conceito para a compreensão de como se articulam os vínculos das pessoas com as empresas empregadoras, o comprometimento organizacional é REAd | Porto Alegre - Edição 76 - N 3 - setembro/dezembro 2013 - p. 675-708 
Fabíola Marinho Costa \& Antonio Virgílio Bittencourt Bastos

um tópico de pesquisa com décadas de desenvolvimento teórico e empírico, que apresenta importantes repercussões para políticas e práticas organizacionais (BECKER; KLEIN; MEYER, 2009). A amplitude, diversidade e longevidade das pesquisas sobre comprometimento foram destacadas por Klein, Molloy e Cooper (2009), que apontam para o reconhecido valor desse construto como uma ferramenta teórica para melhor entender os comportamentos dos trabalhadores e os resultados organizacionais.

Existem múltiplos significados associados ao conceito de comprometimento. Em certo sentido, como afirma Bastos (1994), os usos do termo 'comprometimento' trazem em si a noção de algo que amarra, ata, une o indivíduo a alguma coisa. Ainda que seja possível observar ambiguidades, esse autor aponta que, na esfera científica, comprometimento passou a significar uma adesão, um forte envolvimento do indivíduo com variados aspectos do ambiente de trabalho. Ao discutir as distintas conceituações do construto comprometimento, Klein, Molloy e Cooper (2009) concluem que o comprometimento é mais bem conceituado como um vínculo. Nesse sentido, o comprometimento organizacional é um estado psicológico que reflete o quão fortemente uma pessoa está ligada a uma organização. Na busca por um conceito mais dinâmico, Wright e Kehoe (2009) tratam o comprometimento como um processo ou resultado, mediante o qual indivíduos tornam-se cognitivamente, afetivamente e/ou comportamentalmente ligados a um objeto ou a um curso de ação.

Apesar de muitos estudiosos da área afirmarem que o comprometimento é um processo, há, relativamente, poucas pesquisas conduzidas para examinar como o comprometimento se desenvolve e manifesta sua influência através do tempo (BECKER; KLEIN; MEYER, 2009). Por um lado, o comprometimento tem sido tratado, na maioria dos estudos, como uma variável estática; por outro, há uma ampla defesa, entre os estudiosos, de que o desenvolvimento do comprometimento através do tempo é uma questão crítica para compreender o curso da relação entre o trabalhador e sua organização (BENTEIN et al., 2005).

$\mathrm{Na}$ década de 80, a necessidade de investigações longitudinais foi defendida por estudiosos em suas agendas de pesquisa (MOWDAY; PORTER; STEERS, 1982) e permanece em agendas mais recentes (BECKER; KLEIN; MEYER, 2009; COHEN, 2007b; MEYER et al., 2002; MORROW, 2011; NEININGER et al., 2010). Cooper-Hakim e Viswesvaran (2005), por exemplo, em estudo que examinou, meta-analiticamente, extensiva literatura associada com comprometimento no trabalho, argumentam que há limitações nas conclusões dos estudos transversais, que dominam a área, e afirmam a importância dos 
Transformações em organizações de fruticultura irrigada e a dinâmica do comprometimento organizacional

estudos longitudinais, que possibilitam uma visão dinâmica de como as relações entre as variáveis mudam ao longo do tempo.

Em um mundo do trabalho em mudança, com aumento da competição global, reengenharias e reduções (MEYER; ALLEN, 1997), no qual há menor previsibilidade e menor estabilidade quanto às relações de emprego (BECKER; KLEIN; MEYER, 2009), o comprometimento organizacional torna-se questão de investigação ainda mais importante. De acordo com Kondratuk et al. (2004), pesquisas sugerem que essas mudanças terão um impacto negativo no comprometimento do trabalhador, fragilizando o seu vínculo com a organização em função da reconhecida precarização das condições de trabalho. Diante disso, tornam-se indispensáveis estudos que analisem o quanto as mudanças organizacionais são um potencial redutor do comprometimento dos trabalhadores ao mesmo tempo em que o comprometimento é visto como essencial para a implementação de mudanças bem sucedidas (MEYER, 2009).

Vandenberghe (2009) corrobora essa idéia ao destacar a necessidade de analisar o processo de mudança do comprometimento ao longo do tempo, apontando o estudo dessa mudança como uma importante questão contemporânea. De acordo com Beck e Wilson (2001), dentro da literatura do comprometimento, poucas pesquisas têm focado direta e explicitamente a identificação de mudanças no comprometimento ao longo do tempo ou os fatores associados a essas mudanças. Contudo, os autores defendem que há duas razões para que essas questões sejam consideradas interessantes pelos pesquisadores da área: a primeira razão é acadêmica e diz respeito ao interesse em desenvolver modelos teóricos que expliquem as atitudes e os comportamentos das pessoas; a segunda razão é pragmática e está relacionada ao interesse em propor recomendações aos gestores com vistas a otimizar o comprometimento dos trabalhadores. Essas recomendações, conforme Beck e Wilson (2001), são mais confiáveis quando baseadas em teorias com suporte empírico, que destacam as causas do aumento e decréscimo do comprometimento. Tais reflexões apontam para a necessidade de se investigar como ocorre o desenvolvimento do comprometimento organizacional (MEYER, 2009), reforçando a pertinência da realização de estudos longitudinais, que possibilitem uma análise compatível com a noção de processo, importante para a área do Comportamento Organizacional.

Diante desse cenário, o presente trabalho tem como objetivo avaliar o processo de comprometimento organizacional afetivo (apego com a organização), de comprometimento organizacional de continuação (custos associados a deixar a organização), de percepção de suporte organizacional e de intenção de deixar a organização, associando-os às transformações organizacionais percebidas pelo gestor e trabalhadores de organizações

REAd | Porto Alegre - Edição 76 - N 3 - setembro/dezembro 2013 - p. 675-708 
agrícolas de fruticultura irrigada do polo Juazeiro-BA/Petrolina-PE, visando a melhor compreender as relações entre contexto de trabalho e comprometimento do trabalhador.

Nesse sentido, nas seções seguintes, a título de fundamentação teórica, serão apresentadas as duas perspectivas dominantes do comprometimento organizacional (afetiva e de continuação), a relação do comprometimento organizacional com intenções e comportamentos de afastamento da organização, a percepção de suporte organizacional como um importante preditor do comprometimento organizacional e, por fim, as transformações da fruticultura irrigada do Vale do São Francisco - contexto no qual a pesquisa foi realizada.

\section{REVISÃO DE LITERATURA}

\subsection{Comprometimento organizacional em duas perspectivas dominantes}

Entendido como um construto multidimensional, que pode emergir de diferentes processos psicossociais (ou bases), o comprometimento organizacional apresenta duas perspectivas que mais receberam atenção por parte dos estudiosos: o comprometimento de continuação e o comprometimento afetivo. Essas vertentes têm longa história: o desenvolvimento da perspectiva do comprometimento de continuação foi influenciado pela teoria side-bet, proposta por Howard Becker, em 1960; já o comprometimento afetivo foi inicialmente desenvolvido em 1974, por Porter, Steers, Mowday e Boulian (COHEN, 2007a).

A perspectiva de continuação, originada em concepções sociológicas sobre relações de troca (side-bet), define o comprometimento com a organização como a tendência de o trabalhador nela se manter engajado, devido a percepções individuais sobre custos e benefícios associados a sua saída (MEYER; ALLEN, 1997). Nesse sentido, há uma estreita aproximação entre o processo de comprometimento e o processo de rotatividade, identificando o comprometimento como o principal fator para a explicação da rotatividade voluntária ou, dito de outra forma, a rotatividade como o principal comportamento que poderia ser afetado pelo comprometimento organizacional (COHEN, 2007a).

Já a perspectiva afetiva enfatiza o processo de identificação do indivíduo com os objetivos e valores da organização, e o desejo de manter-se como membro, de modo a facilitar a consecução desses objetivos. Essa abordagem se assenta nas teorias psicológicas sobre ligações afetivas e na concepção de atitudes, refletindo o entendimento de que o indivíduo desenvolve uma forte identificação com a organização e nutre por ela sentimentos e afetos positivos (MEYER; ALLEN, 1997; MOWDAY; PORTER; STEERS, 1982). Os trabalhos desenvolvidos por Mowday, Porter e Steers (1979; 1982) consolidaram uma estratégia de pesquisa definida metodologicamente pelo uso de escalas concebidas a partir do modelo

REAd | Porto Alegre - Edição 76 - N 3 - setembro/dezembro 2013 - p. 675-708 
Transformações em organizações de fruticultura irrigada e a dinâmica do comprometimento organizacional

tripartite, englobando sentimentos, crenças e intenções comportamentais. $\mathrm{O}$ comprometimento, com essa abordagem psicológica, dominou a pesquisa na área por 10 anos (COHEN, 2007b), como um construto alternativo à satisfação no trabalho, por ser um melhor preditor para a rotatividade (COHEN, 2007a) e considerado um processo mais estável (MOWDAY; PORTER; STEERS, 1982). De acordo com esses autores, o comprometimento parece desenvolver-se de forma lenta e constante através do tempo, de modo que eventos transitórios não deveriam causar uma séria reavaliação do empregado acerca do seu vínculo com a organização.

Ao testar a teoria site-bet, Meyer e Allen (1984), inicialmente, propõem um modelo com duas bases, defendendo que além do sentimento de identificação (base afetiva), o comprometimento pode ser descrito a partir da noção de permanência (base de continuação). Posteriormente, Allen e Meyer (1990) propõem o acréscimo de mais uma base para a constituição do conceito de comprometimento organizacional: a base normativa. Por essa perspectiva, trabalhadores comprometidos com sua organização desenvolvem um sentimento de dever e obrigação para com ela. Esse modelo de conceituação do comprometimento organizacional, com três componentes, foi o mais largamente utilizado pelos pesquisadores, tendo sido validado em diversas culturas (COHEN, 2007a, 2007b; MEDEIROS; ENDERS, 1998).

Beck e Wilson (2001) destacam que tanto o comprometimento afetivo quanto o de continuação desenvolvem-se, principalmente, em resposta a experiências atuais em uma organização específica. O comprometimento organizacional afetivo se desenvolve em resposta às experiências do trabalho, que produzem uma realização pessoal ou satisfação de necessidades pessoais, causando no indivíduo uma crença de que eles querem estar comprometidos com a organização. Em contraste, o comprometimento de continuação se desenvolve em resposta ao aumento de investimentos e à falta de alternativas de empregos, ou seja, aos custos associados a deixar a organização (MEYER; ALLEN, 1997). Além da experiência, Beck e Wilson (2001) defendem que o contexto é outro fator que pode estar associado ao desenvolvimento do comprometimento e reforçam a importância de manter contato com o contexto de estudo e afirmam que o comprometimento e o contexto no qual ele existe são interdependentes.

\subsection{O comprometimento organizacional e as intenções e comportamentos de afastamento}

O comprometimento organizacional, classicamente, foi usado para predizer intenções comportamentais (a exemplo de intenção de procurar alternativas de emprego e intenção de

REAd | Porto Alegre - Edição 76 - N 3 - setembro/dezembro 2013 - p. 675-708 
Fabíola Marinho Costa \& Antonio Virgílio Bittencourt Bastos

deixar a organização) e comportamentos de afastamento (como frequência, atraso e rotatividade). Grande parte do destaque que recebeu na área de Comportamento Organizacional deveu-se a ter se revelado um preditor mais forte do que os tradicionais construtos de satisfação e motivação no trabalho. Já na primeira meta-análise conduzida por Mathieu e Zajac (1990), encontrou-se que o comprometimento organizacional possui correlações relativamente altas com as intenções comportamentais, sugerindo que a influência do comprometimento organizacional nos comportamentos é mediada por intenções comportamentais. Outros estudos verificam correlações negativas entre o comprometimento organizacional e intenções comportamentais (a exemplo das intenções de deixar a organização) e comportamentos relacionados à rotatividade, como atraso e absenteísmo (BECKER; KLEIN; MEYER, 2009; BOSWELL et al., 2012; COOPER-HAKIM; VISWESVARAN, 2005; MATHIEU; ZAJAC, 1990; MEYER; ALLEN, 1997; MEYER et al., 2002; NEININGER et al., 2010; VANDENBERGHE, 2009). Essas correlações negativas, de acordo com a meta-análise de Meyer et al. (2002), foram encontradas tanto em relação ao comprometimento afetivo, quanto ao comprometimento de continuação. No entanto, essas correlações são mais fortes quando considerado o comprometimento afetivo (BENTEIN et al. 2005; CHANG; CHI; MIAO, 2007; FELFE; YAN; SIX, 2008; MEYER et al., 2002).

Com o intuito de aumentar a compreensão acerca da rotatividade de empregados nas organizações, Cohen e Freund (2005) examinaram a relação entre múltiplos comprometimentos e a intenção de deixar a organização, utilizando um desenho longitudinal. Os achados da pesquisa enfatizam a importância do tempo, e, consequentemente, dos desenhos longitudinais para a compreensão dessa relação. Segundo os autores, tanto o comprometimento organizacional, como o processo de afastamento dos trabalhadores da organização, desde suas intenções comportamentais à sua efetiva saída, são fenômenos dinâmicos e desenhos transversais não dão conta de esclarecer a natureza dessa relação. Também considerando os aspectos temporais, Culpepper (2011) examinou a relação entre comprometimento e rotatividade. Segundo o autor, consistente com as expectativas, o comprometimento afetivo predisse rotatividade em um intervalo relativamente curto de tempo (quatro meses), embora o mesmo não tenha ocorrido em intervalos de tempo mais longos (cinco a 12 meses). Já o comprometimento de continuação não se apresentou como preditor de rotatividade em curtos intervalos de tempo, mas se mostrou um forte preditor em intervalos de tempo mais longos.

Estudos que identificam o comprometimento organizacional como um preditor para a rotatividade, afirmando que um maior nível de comprometimento reduz a intenção de deixar a

REAd | Porto Alegre - Edição 76 - N 3 - setembro/dezembro 2013 - p. 675-708 
Transformações em organizações de fruticultura irrigada e a dinâmica do comprometimento organizacional

organização (WRITH; KEHOE, 2009), despertam grande interesse, visto que, quanto maior a permanência do indivíduo em uma determinada atividade, menor tende a ser o custo social provocado pela rotatividade do trabalho (MONTE; PENIDO, 2008). Um tempo pequeno de permanência na ocupação, segundo Monte e Penido (2008), tende a acarretar prejuízos para a economia, ao trazer perdas de produtividade para a organização e para o trabalhador, podendo resultar na redução do investimento em capital humano feito pelas organizações. Conforme Paré e Tremblay (2007), uma alta taxa de rotatividade pode aumentar a fragilidade do capital social, as habilidades dentro dos grupos de trabalho e, assim, reduzir as possibilidades de suporte recíproco entre trabalhador e organização.

\subsection{A percepção de suporte organizacional como antecedente do comprometimento}

Teorias da área do Comportamento Organizacional e numerosos estudos empíricos que vêm testando essas teorias têm incluído o comprometimento como um consequente da percepção de suporte organizacional (WAYNE et al., 2009). Esse conceito, que tem sido desenvolvido com base em uma formulação de Eisenberger et al. (1986), refere-se às percepções que os empregados possuem acerca do comprometimento que as organizações empregadoras possuem com eles. $\mathrm{O}$ trabalhador formula opiniões globais sobre o quanto a organização valoriza suas contribuições e cuida do seu bem-estar. Essas opiniões referem-se às crenças do trabalhador sobre o comportamento da organização como um todo e são chamadas de percepção de suporte organizacional (EISENBERGER et al., 1986; SIQUEIRA, 2005; WAYNE et al., 2009; ZAGENCZYK, et al., 2010).

Esse conceito, assim como o de comprometimento, possui como base as teorias de trocas sociais e o princípio de reciprocidade, que propõem que quando uma pessoa ou entidade (que pode ser uma organização) faz um favor à outra, o receptor do favor é obrigado a retribuir (BISHOP et al., 2005; SIQUEIRA, 2005; VANDENBERGHE et al., 2007). Com base na norma de reciprocidade, perceber como favorável o suporte organizacional ajuda a criar um sentido de obrigação em preocupar-se com o bem-estar da organização e ajudá-la a alcançar seus objetivos. Nesse sentido, os empregados pagariam sua dívida se comprometendo afetivamente com a organização (WAYNE et al. 2009).

Essa proposição teórica é reforçada por muitos estudos que têm relatado que a percepção de suporte organizacional e o comprometimento organizacional estão associados (WAYNE et al. 2009). De acordo com Bishop et al. (2005), a revisão da literatura que relaciona esses dois conceitos sugere que quando os trabalhadores percebem que a organização oferece suporte aos empregados, esses apresentam altos níveis de

REAd | Porto Alegre - Edição 76 - N 3 - setembro/dezembro 2013 - p. 675-708 
Fabíola Marinho Costa \& Antonio Virgílio Bittencourt Bastos

comprometimento. Ademais, estudos destacam que há uma influência mais forte da percepção de suporte organizacional no comprometimento afetivo (CASPER et al., 2011; MEYER et al., 2002; MEYER, 2009; SIQUEIRA, 2005; VANDENBERGHE; BENTEIN; STINGLHAMBER, 2004).

Ao examinar a relação entre a percepção de suporte organizacional e o comprometimento organizacional, Rhoades, Eisenberger e Armeli (2001) afirmam que condições de trabalho favoráveis produzem uma percepção do suporte organizacional, que influem no aumento do comprometimento com a organização. Do mesmo modo, os achados de Perry (2004) levam-no a apontar para o fato de que o aumento de demissões e as reestruturações organizacionais fazem decrescer o comprometimento organizacional, baseado na teoria de que o comprometimento é influenciado por mudanças nas normas e condições organizacionais.

Os processos de mudanças vêm sendo reconhecidos como um desafio para o domínio de estudo do comprometimento organizacional (MEYER, 2009). Esses processos envolvem alterações na tecnologia, competição global e demandas do consumidor, que pressionam as organizações a melhorarem sua eficiência, levando-as a responderem de formas variadas, que implicam na redução de empregos, a exemplo de downsizings, reengenharias e fusões (MEYER, 2009). Em uma revisão dos estudos longitudinais sobre comprometimento organizacional afetivo, dos 58 estudos relacionados, Morrow (2011) identificou 13 estudos que davam atenção aos efeitos de mudanças organizacionais e no trabalho sobre o comprometimento. Os estudos, que investigam downsizings e aquisições, descrevem essas mudanças como repercussões negativas sobre o comprometimento. Lee e Corbett (2006), em estudo acerca do impacto do downsizing no comprometimento afetivo dos empregados, afirmam que esse processo afeta indiretamente o comprometimento afetivo dos trabalhadores através de suas experiências diárias de trabalho, como o aumento de atividades e controle. Nesse sentido, é possível supor que os processos de mudanças podem promover alterações nas percepções dos trabalhadores acerca do suporte ofertado pela organização, afetando o comprometimento desses e, consequentemente, impactando na intenção de deixar a organização. Quando considerados esses três construtos, de forma integrada, tornar-se importante voltar-se para uma compreensão mais acurada dos contextos organizacionais e macro sociais em mudança, no qual organizações e trabalhadores estão inseridos.

Em síntese, a relação entre intenções de deixar a organização e a efetiva rotatividade recebeu, ao longo das últimas décadas, forte evidência empírica. São fortes, também, as evidências empíricas de que a percepção do suporte organizacional é um importante preditor

REAd | Porto Alegre - Edição 76 - N 3 - setembro/dezembro 2013 - p. 675-708 
Transformações em organizações de fruticultura irrigada e a dinâmica do comprometimento organizacional

de comprometimento, ao se compreender o comprometimento como um vínculo que se desenvolve e é mantido quando há uma percepção de reciprocidade. A pesquisa na área, no entanto, pouca atenção tem dado em explorar como mudanças contextuais mais amplas podem influenciar a dinâmica dos processos intraorganizacionais que ampliam ou reduzem o comprometimento e, em decorrência, afetam as intenções de permanência e a própria rotatividade. Entretanto, no Handbook de Estudos Organizacionais, Nord e Fox (2004) destacam que se pode observar um deslocamento da ênfase dos estudos organizacionais de uma visão dos indivíduos, independentemente de seu contexto, para a consideração da interação entre os indivíduos e seus contextos organizacionais e sociais. Diante disso, o presente estudo busca suprir esta lacuna ao relacionar elementos do contexto mais geral do mundo do trabalho, no caso específico, do segmento da agroindústria da fruticultura irrigada do baixo médio São Francisco no nordeste brasileiro a processos micro-organizacionais.

\subsection{A fruticultura irrigada do Vale do São Francisco: contexto e transformações}

As transformações no meio rural suscitam um amplo debate no meio científico, em busca de um novo conceito de espaço rural, que tem sido denominado de "novo rural" (SUPERINTENDÊNCIA DE ESTUDOS ECONÔMICOS E SOCIAIS DA BAHIA [SEI], 2003). Estabelecem-se, conjuntamente, no meio rural, uma evolução tecnológica no setor agrícola, uma reorganização dos processos de produção e de trabalho, e uma interação entre as atividades nos espaços rural e urbano. Segundo Fajardo (2008), há um novo padrão agrário, no qual a agricultura se constitui em mais um elo da dinâmica produtiva geral e o espaço agrícola passa a ser comandado pela lógica da ampliação das relações capitalistas no campo. De acordo com o autor, em detrimento da autonomia dos espaços locais, observa-se a imposição de uma lógica global de produção, circulação e consumo na agricultura, que direciona as atividades agrícolas, decidindo o que e onde vai ser produzido.

Mudanças na estrutura econômica e a criação de uma nova organização territorial de produção puderam ser observadas na região do submédio do Vale do São Francisco e abrange áreas dos estados da Bahia e de Pernambuco (SILVA, 2001). Nessa região, destaca-se a fruticultura irrigada no pólo Juazeiro-BA/Petrolina-PE, que tem se caracterizado por apresentar uma rápida expansão da área cultivada, um elevado crescimento da produção e um significativo desenvolvimento do setor exportador de frutas (OLIVEIRA et al., 2008).

A fruticultura no pólo Juazeiro-BA/Petrolina-PE, segundo Silva (2001), surgiu timidamente nos anos 70 e expandiu-se em meados dos anos 80, firmando a região como um importante pólo de produção e exportação de frutas frescas, inseridas nas estruturas de

REAd | Porto Alegre - Edição 76 - N 3 - setembro/dezembro 2013 - p. 675-708 
suprimento internacional de alimentos de alta qualidade. A expansão da fruticultura pôde se apoiar em vantagens comparativas oferecidas pela região, favorecida pela grande potencialidade de recursos naturais, em especial as condições de clima semi-árido tropical, com temperaturas elevadas, alta insolação e grande disponibilidade de água para irrigação. As características climáticas contribuem para que, sob condições de irrigação, seja possível produzir frutas a qualquer época do ano, fora dos limites sazonais (CAVALCANTI; MOTA; SILVA, 2006). Em consequência, permite uma estabilização da produção ao longo do ano, com elevação do número médio de empregos diretos e redução nas tendências sazonais de oferta de emprego (CORREIA; ARAÚJO; CAVALVANTI, 2001).

Apesar de haver uma tendência ao desemprego no campo, em razão, principalmente, das modernas tecnologias - a exemplo do uso de máquinas na cultura da cana-de-açúcar -, a fruticultura irrigada se apresenta como um dos casos de geração de emprego resultante de avanços tecnológicos (SEI, 2003). No entanto, Cavalcanti, Mota e Silva (2006) chamam atenção para o fato de que, apesar do crescimento do emprego na região do vale (dos anos 1980 ao início dos anos 1990), vinculado à expansão das áreas cultivadas e ao aumento da produção, nos últimos anos da década de 1990, o nível de emprego foi reduzido e formas precárias de inserção laboral foram criadas. Os autores acrescentam, ainda, que as estratégias produtivas têm funcionado como redutoras de mão-de-obra efetivamente usada e, em relação aos que permanecem, são seletivas porque requerem novas e atualizadas qualificações.

A expansão da fruticultura, no pólo Juazeiro-BA/Petrolina-PE, de acordo com Silva (2001), viabilizou um processo de reestruturação da agricultura irrigada com repercussões econômicas, sociais e políticas importantes na região. Dentre as mudanças ocorridas, o autor cita alterações significativas: na composição dos produtos cultivados; na base técnica da produção; na estrutura de posse da terra; nos encadeamentos anteriores e posteriores ao processo de produção agrícola; e na estrutura do emprego da região.

Um estudo divulgado pelo Instituto Brasileiro de Geografia e Estatística (IBGE, 2009) traz um diagnóstico socioeconômico da Bacia Hidrográfica do Rio São Francisco, no qual se destaca a agricultura irrigada. De acordo com o estudo, a fruticultura irrigada promoveu a incorporação de terras do semiárido à produção, assim como possibilitou a implantação de um segmento econômico de agroindústria moderna, que tem revelado enorme capacidade de inovação, abrindo novos mercados à exportação do Brasil. Nesse mesmo sentido, Guimarães (2007), após uma visita técnica ao pólo frutícola irrigado de Juazeiro-BA/Petrolina-PE, em 2007, afirmou que esse é o principal pólo local de produção de frutas da América Latina, com o cultivo de 120 mil hectares irrigados (e potencial de 360 mil hectares), gerando 160 mil

REAd | Porto Alegre - Edição 76 - N 3 - setembro/dezembro 2013 - p. 675-708 
Transformações em organizações de fruticultura irrigada e a dinâmica do comprometimento organizacional

postos diretos de trabalho e faturamento anual acima de 600 milhões de dólares. Segundo esse autor, o pólo responde por $50 \%$ das exportações brasileiras de frutas e por $95 \%$ das exportações de manga e uva, frutas que se destacam entre outras cultivadas na região, como goiaba, banana, melancia, melão, acerola, maracujá, limão e pinha.

Muitos dos trabalhadores das organizações investigadas residem no meio rural e, daqueles que não residem atualmente, muitos viveram em um ambiente rural a maior parte de suas vidas. Nesse sentido, mostra-se importante apresentar dados que revelem condições de vida e trabalho da população do campo. De acordo com os dados apresentados pelo IBGE, em 2010, vivem em domicílios rurais cerca de 30 milhões de brasileiros (INSTITUTO DE PESQUISA ECONÔMICA APLICADA [IPEA], 2010). Esse número corresponde a pouco mais de $16 \%$ de toda a população do País, sendo a região Nordeste (região onde se localizam as organizações) aquela que apresenta a maior proporção (27,6\% reside na zona rural), possuindo, também, a maior concentração da população rural do país (48\%).

Ao analisar aspectos socioeconômicos da população rural brasileira, constata-se a baixa escolaridade, as precárias condições de moradia e os reduzidos níveis de renda, o que leva a conclusão de que as dificuldades a que essa população está sujeita produzem, do ponto de vista social, grandes impactos (IPEA, 2010). No que tange às condições de trabalho, dados apresentados pelo IPEA (2010) apontam para o estabelecimento de relações precárias de trabalho no meio rural. O maior contingente de ocupados em atividades agrícolas (43\%) é constituído por trabalhadores não remunerados, seguido por $29 \%$ de empregados, $25 \%$ de trabalhadores por conta própria e 3\% de empregadores. Mais da metade dos trabalhadores agrícolas $(68 \%)$ está fora de qualquer relação de assalariamento, o que, conforme o autor, desafia a estrutura do sistema de direitos e garantias sociais, fundadas nas relações de trabalho centradas no emprego formal. Observa-se, também, uma alta taxa de participação dos trabalhadores temporários, com $43 \%$ do total de empregados ocupados, que sintetiza algumas das características ainda dominantes na área rural: sazonalidade das ocupações, relações de trabalho altamente instáveis, baixos salários, trabalho braçal e péssimas condições de trabalho. Os dados revelam que tanto o emprego temporário quanto o emprego permanente possuem uma taxa elevada de informalidade, dificultando o acesso desses trabalhadores aos direitos que compõem o patrimônio social associado às relações de trabalho.

É possível supor que o estabelecimento de relações precárias de trabalho no pólo frutícola de Juazeiro-BA/Petrolina-PE tenha sido acentuado durante o que se caracterizou como uma crise no Vale do São Francisco. Em meados de 2007, iniciou-se, nos Estados Unidos da América, uma crise econômica mundial, cuja origem encontra-se na derrocada do

REAd | Porto Alegre - Edição 76 - N 3 - setembro/dezembro 2013 - p. 675-708 
mercado de hipotecas (DULCI, 2009). Essa crise produziu efeitos de contágio sobre as principais praças financeiras do mundo e demandou ações de política econômica de múltiplos países, para tentar conter os impactos sobre o sistema produtivo (IPEA, 2009a). De acordo com Dulci (2009), o Brasil ficou relativamente protegido do desastre do sistema financeiro dos Estados Unidos e da Europa. Entretanto, a crise atingiu a produção e o comércio do país com a queda de preços dos produtos básicos de exportação, ou commodities, matérias-primas e alimentos. A redução da renda e da demanda mundial teve importantes efeitos sobre as exportações brasileiras. Com a crise internacional, os agricultores reclamaram de um descompasso entre custo de produção e preço de venda, em vista da alta dos preços dos insumos, em um momento em que os preços internacionais dos principais produtos estavam caindo (IPEA, 2009b).

Diante disso, a crise econômica mundial impactou profundamente no processo de produção e comercialização das frutas do pólo agrícola do Vale do São Francisco. Em razão da crise, verificou-se uma queda do consumo dessas frutas no exterior, seguida pela suspensão das compras antecipadas, realizadas pelos importadores europeus e norte-americanos, que financiavam a produção. Esse cenário acarretou importantes consequências, como: redução da safra, queda do preço das frutas, fechamento temporário de fazendas produtoras das frutas e demissão de empregados.

Acrescenta-se, ainda, o fato de que houve frequentes perdas de safra pelas chuvas fora de época, culminando, entre 2007 e 2008, em uma significativa redução no faturamento das exportações. Oliveira, Rigo e Carvalho (2009) explicam que as irregularidades da chuva influenciaram na qualidade do produto, o que provocou uma queda média de $20 \%$ do volume exportado, levando os produtores a repassarem as frutas não exportadas para o mercado interno, onde o excesso de oferta provocou queda no preço das frutas. Os autores relacionam três fatores que contribuíram para este cenário de forte crise que atingiu o agronegócio brasileiro: quebras de safra decorrentes de variações climáticas; queda nos preços de commodities agrícolas, devido a sua superprodução nos principais países fornecedores; e câmbio desfavorável na comercialização da produção.

Esse contexto com tantas e intensas transformações, com amplas consequências econômicas, sociais e culturais para uma região historicamente subdesenvolvida, apresenta-se como um campo fértil para se estudar a dinâmica dos vínculos estabelecidos entre esses trabalhadores e as organizações agrícolas. Adicionalmente, com raras exceções como as dos estudos desenvolvidos por F. M. Costa (2005), Costa e Bastos (2009) e V. M. F. Costa (2007), faltam pesquisas que analisem o comprometimento organizacional entre trabalhadores

REAd | Porto Alegre - Edição 76 - N 3 - setembro/dezembro 2013 - p. 675-708 
Transformações em organizações de fruticultura irrigada e a dinâmica do comprometimento organizacional

agrícolas, visto que as pesquisas na área, em sua grande maioria, descrevem a realidade do trabalhador urbano e dos segmentos industrial e de serviço.

\section{MÉTODO}

O estudo acompanhou, ao longo de dois anos, trabalhadores agrícolas de organizações de fruticultura irrigada com o intuito de analisar simultaneamente, o desenvolvimento do processo de comprometimento afetivo (CA) e de comprometimento de continuação (CC), assim como de percepção de suporte organizacional (PSO) e de intenção de deixar a organização (IDO), considerados pela literatura, respectivamente, como um antecedente e um consequente do comprometimento organizacional $(\mathrm{CO})$. A pesquisa implica, também, em acompanhar as transformações organizacionais percebidas pelo gestor e trabalhadores, visando a melhor compreender as relações entre contexto de trabalho e comprometimento do trabalhador. Foram realizadas entrevistas em quatro momentos diferentes, com, aproximadamente, seis meses de intervalo. Utilizou-se, assim, um tipo de desenho temporal de pesquisa, nomeado de painel longitudinal. De acordo com Collins (2006), o painel longitudinal é definido como um desenho onde há relativamente poucos casos de medidas (oito medidas ou menos), e as observações estão separadas por, no mínimo, seis meses. Embora não exista um período de tempo definido a priori como desejável para se acompanhar um fenômeno psicossocial em contextos organizacionais e tal definição se deva, fortemente, a condições e recursos para realização da pesquisa, os poucos estudos longitudinais sobre comprometimento realizam três medidas em intervalo de tempo de seis meses a um ano. No presente estudo, optamos por quatro medidas no período de dois anos, tempo que permitiu captar a influência do contexto de crise na agroindústria da fruticultura irrigada sobre o vínculo do trabalhador. Participaram da pesquisa três organizações agrícolas de fruticultura irrigada, localizadas na região do pólo Juazeiro-BA/Petrolina-PE. Essas organizações pertencem a um mesmo grupo econômico, considerado um dos maiores exportadores do Vale do São Francisco. Essas características, aliada à disponibilidade para participar da pesquisa, justificaram a escolha dessas organizações. As empresas, instaladas na região desde a década de 1980, estão voltadas para a exportação de manga e uva para mercados como Comunidade Européia e Estados Unidos da América (EUA). Até chegar ao consumidor final, os produtos passam por vários estágios, o que inclui rigorosos cuidados com a higienização das frutas desde a colheita. No packing house (expressão de língua inglesa que pode ser traduzida como “casa para embalagem”) as frutas são rigorosamente avaliadas em relação a: maturação, danos, colorido, qualidade da colheita e transporte. Em seguida, as frutas são submetidas a: 
Fabíola Marinho Costa \& Antonio Virgílio Bittencourt Bastos

limpeza, seleção de refugo, seleção para embalagem de acordo com o mercado, embalagem, paletização, resfriamento e armazenagem.

Os contatos com os participantes da pesquisa aconteceram nos anos de 2007 e 2008. Procurou-se manter o número constante da amostra por organização, incluindo novos trabalhadores em substituição aos que não puderam participar das etapas seguintes, em casos como demissão ou férias. Nos quatro tempos, responderam ao questionário, respectivamente, 114, 135, 162 e 162 trabalhadores. O número de participantes foi definido em função do número total de trabalhadores e das dificuldades e demora em realizar entrevistas individuais com trabalhadores de baixa escolaridade, durante seu trabalho. Inicialmente, foi definido como meta o mínimo de 100 trabalhadores. Esse número foi aumentado a partir da segunda aplicação ao se constatar o elevado índice de perdas de participantes. Na Tabela 1 estão apresentadas as características dos participantes por coleta nos quatro tempos.

Ao final da pesquisa, 266 trabalhadores foram entrevistados (grupo total), sendo que 46 desses responderam ao questionário nos quatro momentos (grupo constante), devido à elevada taxa de rotatividade e da redução de quadros em função da crise, além de fatores imprevistos como a ausência do trabalhador na empresa nos dias da entrevista (havia casos de férias ou afastamentos por motivo de saúde, por exemplo). Em cada um dos quatro momentos, há uma amostra representativa do conjunto de trabalhadores das organizações, o que permite identificar possíveis fatores que estão afetando o conjunto de trabalhadores como um todo. São medidas importantes para verificar as mudanças, tendo como unidade de análise as organizações participantes. Por outro lado, a comparação intragrupos (os mesmos trabalhadores avaliados em quatro momentos distintos do tempo) permite avaliar se as mudanças identificadas ocorrem também no nível dos trabalhadores. Na Psicologia, por tomar preferencialmente o indivíduo como unidade de análise, essa comparação do grupo constante é importante. O estudo, ao trabalhar simultaneamente com os grupos nos quatro momentos e com o grupo constante, combinando uma análise intergrupos e intragrupo, possibilita identificar evidências que venham a fortalecer a hipótese de que mudanças macro ambientais e organizacionais afetam o nível de comprometimento dos indivíduos. O importante, no entanto, é que no grupo constante observou-se um perfil similar ao do grupo total com predomínio de: homens $(69,6 \%)$; casados $(78,3 \%)$; relativamente jovens, com idade entre 26 a 35 anos (54,3\%); que possuíam baixa escolaridade, com ensino fundamental incompleto $(52,2 \%)$. No que se refere ao tempo de trabalho, no tempo $4,31,1 \%$ dos trabalhadores possuíam entre 1 e 2 anos de trabalho e outros 31,1\% possuíam entre 3 e 5 anos de trabalho. Para a coleta de dados foi utilizado um questionário estruturado. Como o estudo envolveu REAd | Porto Alegre - Edição 76 - N 3 - setembro/dezembro 2013 - p. 675-708 
Transformações em organizações de fruticultura irrigada e a dinâmica do comprometimento organizacional

categorias concentradoras de pessoas com baixa escolaridade, foram utilizados recursos não verbais, com gradações de tonalidades de cores (vermelho para discordo; amarelo para nem concordo, nem discordo; verde para concordo) em substituição às escalas tradicionais, viabilizando a utilização de escalas do tipo Likert de sete pontos com essa população. Para mensurar o CA foram utilizados oito dos nove itens recomendados por Bastos (1994). O autor propôs a redução da versão completa da escala de Mowday, Porter e Steers (1982), traduzida e adaptada para o contexto brasileiro por Borges-Andrade, Afanasieff e Silva (1989), ao retirar itens relacionados a intenções comportamentais, diminuindo de 15 para nove itens. Também foram utilizados mais seis itens da escala de CA proposta por Meyer e Allen (1997).

Tabela 1 - Características dos participantes por coleta nos quatro tempos.

\begin{tabular}{|c|c|c|c|c|c|c|c|c|}
\hline \multirow{2}{*}{ Variáveis } & \multicolumn{2}{|c|}{ Tempo 1} & \multicolumn{2}{|c|}{ Tempo 2} & \multicolumn{2}{|c|}{ Tempo 3} & \multicolumn{2}{|c|}{ Tempo 4} \\
\hline & $\mathrm{n}$ & $\%$ & $\mathrm{n}$ & $\%$ & $\mathrm{n}$ & $\%$ & $\mathrm{n}$ & $\%$ \\
\hline \multicolumn{9}{|l|}{ Sexo } \\
\hline Masculino & 77 & 67,5 & 95 & 70,4 & 115 & 71,0 & 120 & 74,1 \\
\hline Feminino & 37 & 32,5 & 40 & 29,6 & 47 & 29,0 & 42 & 25,9 \\
\hline \multicolumn{9}{|l|}{ Estado Civil } \\
\hline Casado / vive junto & 58 & 50,9 & 98 & 72,6 & 110 & 67,9 & 120 & 74,1 \\
\hline Solteiro & 49 & 43,0 & 32 & 23,7 & 44 & 27,2 & 37 & 22,8 \\
\hline Outro & 7 & 6,1 & 5 & 3,7 & 8 & 4,9 & 5 & 3,1 \\
\hline \multicolumn{9}{|l|}{ Idade } \\
\hline Até 25 anos & 22 & 19,3 & 30 & 22,2 & 35 & 21,6 & 31 & 19,1 \\
\hline De 26 a 35 anos & 57 & 50,0 & 64 & 47,4 & 72 & 44,4 & 73 & 45,1 \\
\hline De 36 a 45 anos & 15 & 13,2 & 18 & 13,3 & 32 & 19,8 & 34 & 21,0 \\
\hline Acima de 45 anos & 20 & 17,5 & 23 & 17,0 & 23 & 14,2 & 24 & 14,8 \\
\hline \multicolumn{9}{|l|}{ Escolaridade } \\
\hline Nunca estudou & 9 & 8,0 & 6 & 4,4 & 10 & 6,2 & 9 & 5,6 \\
\hline $\begin{array}{l}\text { Ensino fundamental } \\
\text { incompleto }\end{array}$ & 56 & 49,6 & 72 & 53,3 & 71 & 43,8 & 79 & 48,8 \\
\hline $\begin{array}{l}\text { Ensino fundamental } \\
\text { completo }\end{array}$ & 18 & 15,9 & 19 & 14,1 & 28 & 17,3 & 27 & 16,7 \\
\hline Ensino médio & 25 & 22,1 & 33 & 24,4 & 50 & 30,9 & 46 & 28,4 \\
\hline Ensino superior & 5 & 4,4 & 5 & 3,7 & 3 & 1,9 & 1 & 0,6 \\
\hline \multicolumn{9}{|l|}{ Tempo de trabalho } \\
\hline Até 11 meses & 49 & 43,4 & 24 & 17,8 & 19 & 11,7 & 14 & 8,7 \\
\hline De 12 a 35 meses & 31 & 27,4 & 57 & 42,2 & 70 & 43,2 & 61 & 37,9 \\
\hline De 36 a 59 meses & 18 & 15,9 & 24 & 17,8 & 36 & 22,2 & 43 & 26,7 \\
\hline De 60 a 83 meses & 8 & 7,1 & 16 & 11,9 & 17 & 10,5 & 26 & 16,1 \\
\hline Acima de 83 meses & 7 & 6,2 & 14 & 10,4 & 20 & 12,3 & 17 & 10,6 \\
\hline
\end{tabular}

Fonte: dados da pesquisa.

Para o CC, foram utilizados os seis itens da escala proposta por Meyer e Allen (1997), mais um item proposto por Siqueira (1995). As medidas propostas por Meyer e Allen (1997) 
Fabíola Marinho Costa \& Antonio Virgílio Bittencourt Bastos

foram previamente validadas para o contexto nacional por Medeiros e Enders (1998). Os trabalhadores foram questionados sobre suas percepções acerca do suporte organizacional e sobre a IDO, com medidas construídas pelo grupo de pesquisa.

O procedimento de coleta dos dados seguiu os seguintes passos: (1) teste piloto - foi realizado um pré-teste do instrumento de coleta de dados, no qual se atentou para o controle do tempo de aplicação e a importância do instrumento estar redigido em linguagem acessível à compreensão dos respondentes; (2) contato e consentimento - foram contatados, nas organizações, os trabalhadores que, em pesquisa anteriormente realizada pelo grupo de pesquisa, atestaram concordância em participar, mediante Termo de Consentimento Livre e Esclarecido, e se dispuseram a contribuir em outro momento de coleta de dados; (3) aplicação dos questionários - os questionários foram preenchidos por membros do grupo de pesquisa, em razão da baixa escolaridade dos participantes, no contexto de trabalho e no horário de expediente; a maioria das entrevistas ocorreu, assim, no próprio campo, nas plantações de uva ou de manga, quanto o trabalhador interrompia o seu trabalho para participar do estudo; as entrevistas dos trabalhadores administrativos e de packing house ocorreram em salas nestes ambientes de trabalho; ao final do questionário, foi perguntado ao trabalhador sobre suas percepções acerca das transformações ocorridas na organização nos últimos seis meses; (4) entrevista - após a coleta de dados nos quatro tempos, foi realizada uma entrevista com o gestor acerca das transformações ocorridas na organização durante o período da investigação.

Os processos de tratamento e análise de dados foram iniciados com as codificações das respostas e a preparação do banco de dados com a utilização de um pacote estatístico, permitindo que o grupo de trabalhadores, como um todo, fosse tomado como uma unidade de análise. Foram realizadas análises descritivas simples (frequências, médias e desvios-padrão), comparação de médias (teste $t$ para amostras dependentes) e correlações. Considerando a normalidade dos dados e o uso de medidas intervalares, foi utilizado o coeficiente de correlação de Pearson. Foram consideradas estatisticamente significantes as diferenças que apresentaram um $\mathrm{p}<0,05$. Também foram realizadas análises de fatores. A adequação da amostra foi avaliada com o uso do teste Kaiser-Meyer-Olkin (KMO). Também foi utilizado o teste de esfericidade de Barlett, que indica a presença de correlações significativas entre as variáveis. As entrevistas com o gestor foram registradas em gravador digital de voz, realizando-se posterior transcrição verbatim e digitação em computador. A partir da leitura das falas do gestor e dos trabalhadores, na questão aberta sobre as transformações organizacionais, foram elaboradas categorias analíticas, mediante as quais os dados foram categorizados.

REAd | Porto Alegre - Edição 76 - N 3 - setembro/dezembro 2013 - p. 675-708 
Transformações em organizações de fruticultura irrigada e a dinâmica do comprometimento organizacional

\section{RESULTADOS E DISCUSSÃO}

Inicialmente, são apresentados os resultados relativos às transformações organizacionais percebidas pelo gestor, seguidas daquelas percebidas pelos trabalhadores. Posteriormente, são apresentados os resultados que descrevem a dinâmica do CA e do CC, assim como da PSO e da IDO, na amostra total dos participantes em cada tempo e na amostra dos 46 trabalhadores que participaram dos quatro tempos da investigação.

\subsection{Percepções acerca das transformações organizacionais}

Para melhor compreender a tendência dos dados ao longo do tempo, as percepções do gestor sobre as transformações ocorridas nas organizações investigadas, durante o período da coleta de dados, são apresentadas na Figura 1. No período da investigação, foram percebidas transformações organizacionais, como a redução de quadro e reestruturação de setores, e transformações no ambiente externo às organizações, com impacto direto sobre essas, a exemplo da queda de preços das frutas no mercado norte-americano.

- Um dos melhores anos.

- Atividade altamente rentável.

- Não tinha problemas.
- Início da crise no Vale do São Francisco.

No ambiente organizacional:

- Queda de preços das frutas.

- Aumento nos custos.

- Calote dos compradores.

Nas organizações:

- Construção do packing house.

- Redução de áreas plantadas.

- Falta de equipamentos de proteção.

- Atrasos no pagamento do salário.

- Demissões.
- Sérias dificuldades financeiras.

No ambiente organizacional:

- Redução na compra de frutas.

- Queda no valor do produto.

- Negociação com o sindicato.

- Oferta de emprego mais reduzida.

Nas organizações:

- Atraso nos pagamentos.

- Greve dos trabalhadores.

- Falta de dinheiro para demitir.

- Redução do número de empregados.

- Reestruturação de cargos e atividades.

- Introdução do ganho por produtividade.

- Redução da safra.

- Mudanças no manejo do cultivo.

- Revisão nas orientações para o trabalho.

\begin{tabular}{c|c|c|c|c} 
& Tempo 1 & Tempo 2 & Tempo3 & Tempo 4 \\
\hline 2006 & 2007 & 2008
\end{tabular}

Figura 1 - Linha do tempo com as percepções do gestor sobre as transformações ocorridas nas organizações durante 2007 e 2008.

Fonte: dados da pesquisa.

O ano de 2006, período anterior à investigação, apresenta-se como o ápice da rentabilidade das atividades desenvolvidas pelas organizações e serve como um parâmetro para compreensão das consequências das transformações que ocorreram nos anos posteriores. O ano de 2007 é caracterizado pelo início de uma crise no Vale do São Francisco, com queda de preços das frutas, aumento nos custos e calote dos compradores, e consequentes dificuldades financeiras nas organizações. Já o ano de 2008 representa o auge da crise, 
Fabíola Marinho Costa \& Antonio Virgílio Bittencourt Bastos

marcada por uma greve dos trabalhadores e pela demissão de $30 \%$ desses, seguida pelos primeiros sinais de reação às dificuldades vivenciadas.

Também foram investigadas as percepções dos trabalhadores sobre as transformações ocorridas na organização, desde a visita anterior do grupo de pesquisa, que são apresentadas na Figura 2. Nos tempos 2, 3 e 4, 55\%, 62\% e 43\% dos respondentes, respectivamente, afirmaram que perceberam transformações na empresa nos períodos em questão. Embora parte dos trabalhadores não tenha citado nenhuma transformação, é possível supor que os fatos ocorridos nas organizações, ainda que não citados ou não percebidos por alguns, devam ter afetado os trabalhadores em geral. No tempo 2, 29,7\% dos respondentes relataram ter percebido transformações na estrutura física da empresa. Foram relatadas, também, transformações no ambiente social, seja em relação aos superiores (mudanças de chefia) ou aos colegas de trabalho (mudanças no quadro de funcionários). Outra transformação citada, nesse tempo, diz respeito ao processo de trabalho.

Já nos tempos 3 e 4, a transformação mais citada foi com relação ao atraso nos salários dos trabalhadores $(36,4 \%$ e $16,4 \%$ dos respondentes, respectivamente), o que culminou em uma greve. Para esse grupo de trabalhadores, mudou o ambiente físico, a pessoa que os supervisionava, as pessoas com quem trabalhavam, o modo como trabalhavam e a certeza do pagamento no dia acordado. Entende-se que essas transformações tenham impactado diretamente as experiências diárias de trabalho, que, por sua vez, podem ter afetado as relações estabelecidas entre trabalhador e organização.

Muitas das transformações organizacionais percebidas pelo gestor, assim como as percebidas pelos trabalhadores, encontram-se relacionadas ao macro contexto no qual estão inseridas as organizações. Os EUA estavam comprando as frutas por um melhor preço que a Europa e muitos produtores direcionaram suas exportações para aquele mercado consumidor. Com isso, houve um volume concentrado de exportações para um só mercado, que, com a crise mundial, reduziu a compra de frutas, gerando queda nos preços. Diante da lógica global de produção, circulação e consumo de mercadorias, que direciona as atividades dessas organizações, a crise econômica, que atingiu o principal mercado consumidor, gerou impactos no nível organizacional (p. ex. reestruturação de setores), assim como no cotidiano dos trabalhadores, dentro (p. ex. mudanças no processo de trabalho) ou fora do ambiente de trabalho (p. ex. atraso do recebimento do salário e demissão). 
Transformações em organizações de fruticultura irrigada e a dinâmica do comprometimento organizacional

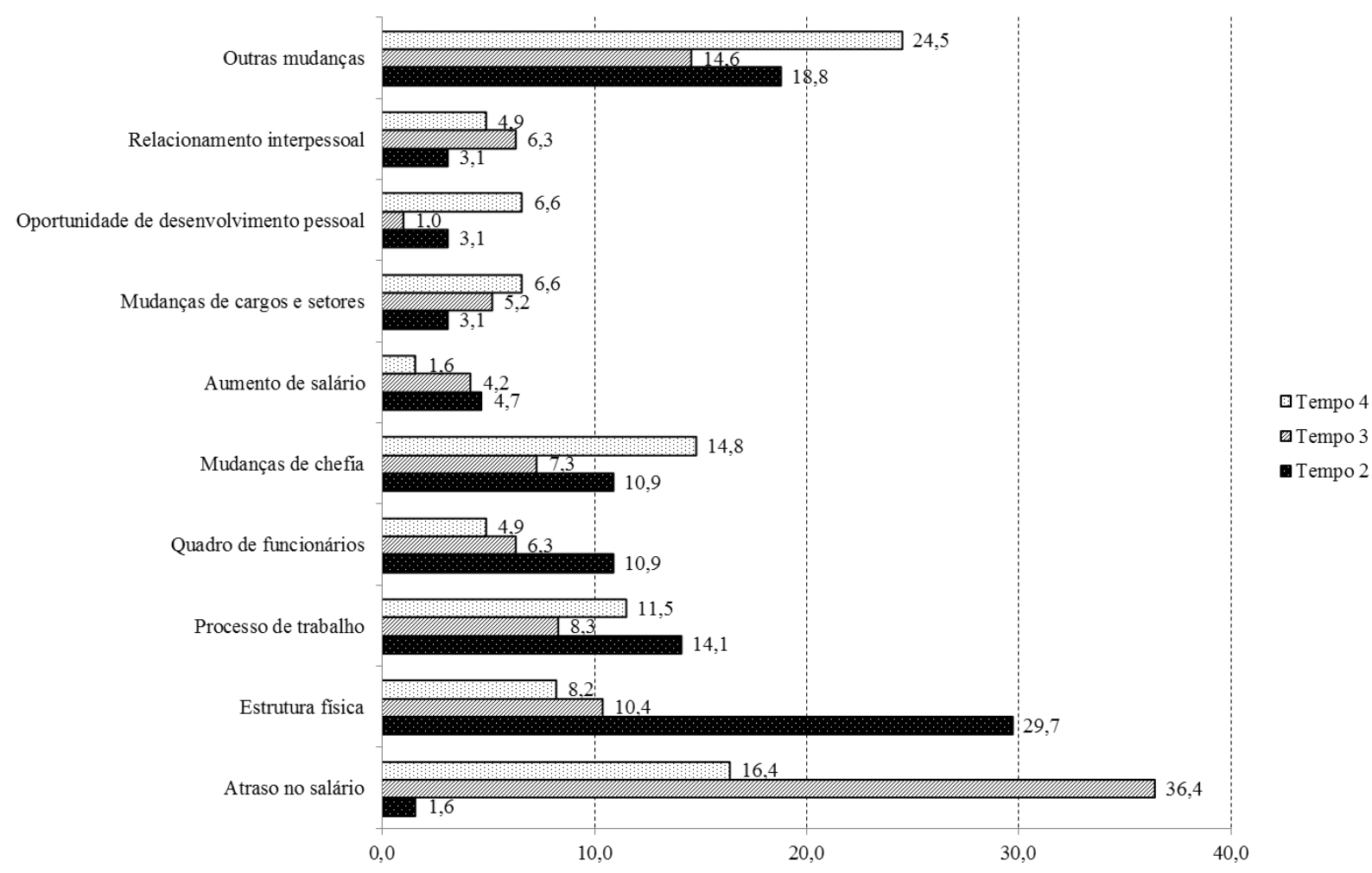

Figura 2 - Transformações percebidas pelos trabalhadores nas organizações durante 2007 e 2008. Fonte: dados da pesquisa.

Ao longo do período do estudo, importantes transformações foram percebidas no ambiente no qual as organizações estão inseridas e em diferentes dimensões das organizações, suscitando alguns questionamentos. Essas transformações foram acompanhadas por alterações nas percepções dos trabalhadores sobre o quanto a organização valoriza suas contribuições e cuida do seu bem-estar? Essas transformações foram acompanhadas por alterações na identificação do indivíduo com os objetivos e valores da organização ou no desejo de manterse como membro? Essas transformações foram acompanhadas por alterações na intenção de deixar a organização? Ao considerar que esses processos psicossociais e o contexto no qual eles se desenvolvem são interdependentes, e que esses processos podem ser influenciados por mudanças nas condições organizacionais, a seguir, são apresentadas as dinâmicas do CO, da PSO e da IDO entre os trabalhadores, ao longo dos dois anos de investigação.

3.2. Dinâmica do comprometimento organizacional ao longo dos quatro tempos

As escalas de CA, de CC, de PSO e de IDO obtiveram bons índices de consistência interna. Com exceção da escala de CC no tempo $4(\alpha=0,69)$, todos os coeficientes Alfas de Cronbach encontram-se acima de 0,70, nas amostras dos quatro tempos investigados, o que é indicador da confiabilidade das medidas utilizadas, mesmo considerando a especificidade da amostra de trabalhadores agrícolas. Para avaliar a consistência das medidas, ao longo do

REAd | Porto Alegre - Edição 76 - N 3 - setembro/dezembro 2013 - p. 675-708 
Fabíola Marinho Costa \& Antonio Virgílio Bittencourt Bastos

tempo, foram realizadas análises fatoriais. A medida KMO apresentou valores a partir de 0,80 , nos quatro tempos $(0,80 ; 0,89 ; 0,91 ; 0,85$; respectivamente $)$, relevando a adequação da amostra. O teste de Barlett apresentou valores significativos (significância menor do que 0,05), demonstrando que a análise dos fatores é apropriada. Em todos os tempos, verificou-se a distinção entre os fatores e a unidimensionalidade dos construtos. Em geral, as correlações entre as variáveis não excederam 0,70 , indicando que não há problemas de multicolinearidade, exceto a correlação entre CA e PSO no tempo $2(r=0,73, p \leq 0,01)$. Entre as variáveis estudadas (CA, CC e PSO), foram verificadas correlações positivas com modestas magnitudes, o que sugere que a sobreposição dos conceitos não é excessiva e nem resulta em redundância.

A partir das análises descritivas, apresentadas na Tabela 2, observa-se a dinâmica das variáveis investigadas, na amostra total de trabalhadores nos tempos 1, 2, 3 e 4 (grupo total) e na amostra dos 46 trabalhadores que participaram em todos os quatro momentos de coleta de dados (grupo constante). Ressalta-se que o grupo constante apresentou perfil sóciodemográfico similar ao grupo total, o que possibilita ampliar o poder de generalização dos resultados encontrados no pequeno grupo que foi acompanhado durante os dois anos.

Tabela 2 - Médias e desvios padrões de CA, CC, PSO e IDO no grupo total e no grupo constante

\begin{tabular}{|c|c|c|c|c|c|c|c|c|c|c|c|c|}
\hline \multirow[t]{2}{*}{ Variáveis* } & \multicolumn{3}{|c|}{ Tempo 1} & \multicolumn{3}{|c|}{ Tempo 2} & \multicolumn{3}{|c|}{ Tempo 3} & \multicolumn{3}{|c|}{ Tempo 4} \\
\hline & $\mathbf{M}$ & DP & n & $\mathbf{M}$ & DP & $\mathbf{n}$ & $\mathbf{M}$ & DP & $\mathbf{n}$ & $\mathbf{M}$ & DP & $\mathbf{N}$ \\
\hline \multicolumn{13}{|l|}{ Grupo total } \\
\hline $\mathrm{CA}$ & 5,47 & 1,09 & 114 & 5,12 & 1,26 & 135 & 4,83 & 1,35 & 162 & 4,80 & 1,16 & 162 \\
\hline $\mathrm{CC}$ & 5,10 & 1,28 & 114 & 4,84 & 1,24 & 135 & 4,76 & 1,24 & 162 & 4,63 & 1,16 & 162 \\
\hline PSO & 4,88 & 1,25 & 114 & 4,74 & 1,19 & 135 & 4,36 & 1,30 & 162 & 4,45 & 1,25 & 162 \\
\hline IDO & 4,64 & 1,53 & 114 & 4,98 & 1,52 & 135 & 5,21 & 1,34 & 162 & 5,02 & 1,62 & 161 \\
\hline \multicolumn{13}{|l|}{ Grupo constante } \\
\hline CA & 5,43 & 1,12 & 46 & 5,30 & 1,18 & 46 & 4,93 & 1,24 & 46 & 4,86 & 1,22 & 46 \\
\hline $\mathrm{CC}$ & 5,19 & 1,19 & 46 & 5,17 & 1,18 & 46 & 4,82 & 1,14 & 46 & 4,79 & 1,20 & 46 \\
\hline PSO & 4,93 & 1,45 & 46 & 4,81 & 1,23 & 46 & 4,28 & 1,45 & 46 & 4,39 & 1,18 & 46 \\
\hline IDO & 4,55 & 1,61 & 46 & 4,76 & 1,65 & 46 & 5,09 & 1,60 & 46 & 4,90 & 1,66 & 45 \\
\hline
\end{tabular}

* Escala de sete pontos.

Fonte: dados da pesquisa.

A dinâmica das médias, no grupo total de trabalhadores, pode ser mais bem visualizada na Figura 3, na qual se observou uma redução nos níveis de CA $(5,47 ; 5,12 ; 4,83 ; 4,80$; nos 
Transformações em organizações de fruticultura irrigada e a dinâmica do comprometimento organizacional

tempos 1, 2, 3 e 4, respectivamente) no decorrer dos quatro tempos. A tendência à redução das médias também foi observada nos níveis de CC $(5,10 ; 4,84 ; 4,76 ; 4,63$; nos tempos $1,2,3$ e 4 , respectivamente).

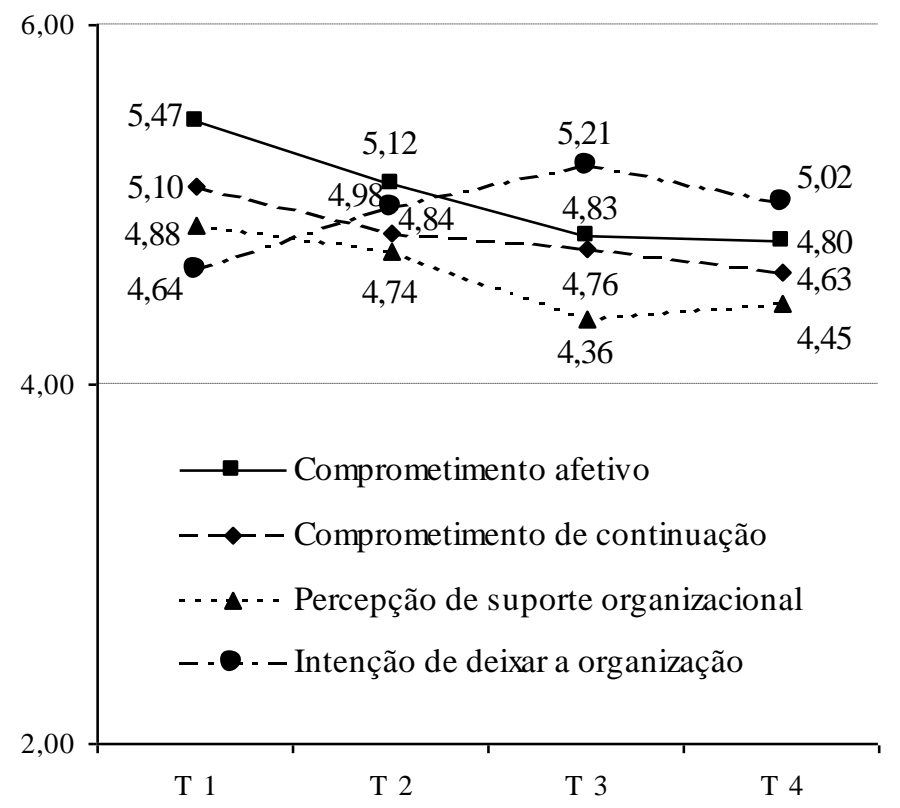

Figura 3 - Médias de CA, CC, PSO e IDO, no grupo total, nos quatro tempos. Fonte: Tabela 2

Quando analisadas as percepções que os trabalhadores possuem acerca do suporte que a organização oferece a eles, consideradas como antecedente do comprometimento, observou-se que os níveis de PSO reduziram entre o primeiro e o terceiro tempo $(4,88 ; 4,74 ; 4,36$; respectivamente), acompanhando a queda dos níveis de comprometimento. Do tempo 3 para o tempo 4 , houve um aumento na média, mas que não possibilitou o alcance das médias obtidas nos tempos anteriores. Observa-se, ainda, um aumento nos níveis de IDO entre o tempo 1 e 3 $(4,64 ; 4,98 ; 5,21$, respectivamente), seguida de uma ligeira queda do nível no tempo $4(5,02)$. Nos três primeiros tempos, enquanto os níveis dos comprometimentos organizacionais reduziam, aumentavam os níveis de IDO.

A comparação do grupo total de trabalhadores com o grupo constante aponta para similaridades entre esses grupos: redução dos níveis de CA e de CC; redução do nível de PSO até o tempo 3; aumento nos níveis de IDO até o tempo 3 e queda no tempo 4. Para analisar se as diferenças entre as médias dos comprometimentos no grupo constante são estatisticamente significativas, foi utilizado o teste $t$ dependente. Essa análise está representada na Figura 4.

Na média, o grupo constante apresentou um maior CA no tempo $2(\mathrm{M}=5,30, \mathrm{M}=0,17)$ do que no tempo $3(\mathrm{M}=4,93, \mathrm{EP}=0,18, t(45)=2,40, \mathrm{p}<0,05, r=0,64)$. Comparando as médias de CA entre os tempos 1 e 2 e entre os tempos 3 e 4 , não foram encontradas diferenças 
Fabíola Marinho Costa \& Antonio Virgílio Bittencourt Bastos

estatisticamente significativas. Portanto, para esse grupo de trabalhadores, observa-se uma redução do CA entre os tempos 2 e 3 . Na análise do $\mathrm{CC}$, também se observa uma redução na média do tempo 2 para o 3. Na média, o grupo constante apresentou um maior CC no tempo 2 $(\mathrm{M}=5,17, \mathrm{EP}=0,17)$ do que no tempo $3(\mathrm{M}=4,82, \mathrm{EP}=0,17, t(45)=2,33, \mathrm{p}<0,05, r=$ $0,62)$.

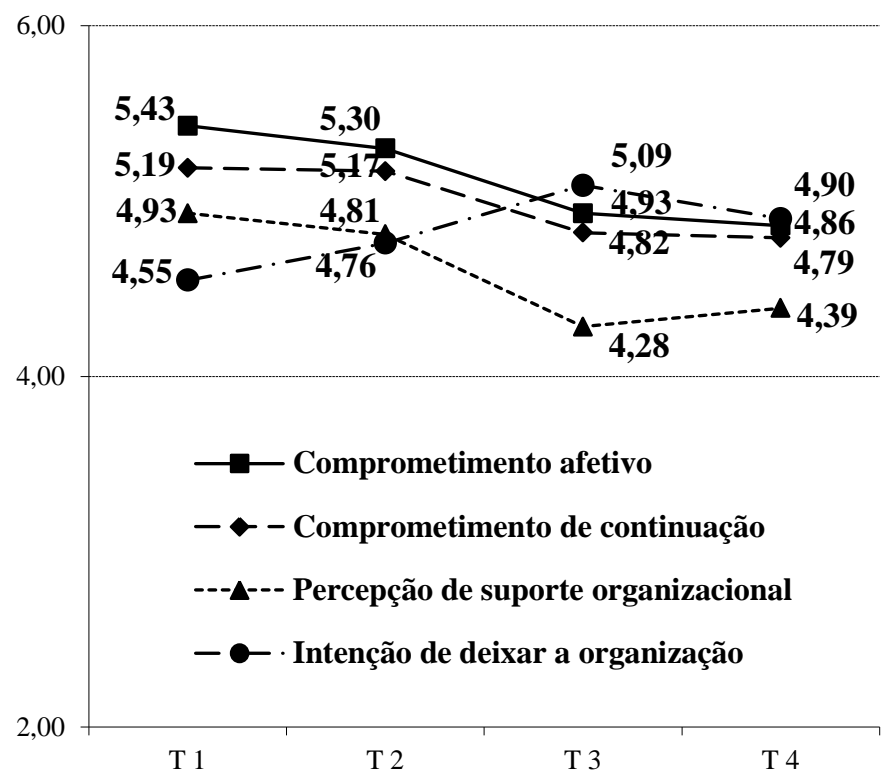

Figura 4 - Médias de CA, CC, PSO e IDO, no grupo constante, nos quatro tempos. Fonte: Tabela 2.

Ao considerar as médias de PSO, o grupo constante apresentou uma maior média no tempo $1(\mathrm{M}=4,93, \mathrm{EP}=0,21)$ do que no tempo $3(\mathrm{M}=4,28 \mathrm{EP}=0,21, t(45)=3,30, \mathrm{p}<$ $0,05, r=0,58)$, assim como entre o tempo $2(\mathrm{M}=4,81, \mathrm{EP}=0,18)$ e $3(\mathrm{M}=4,28 \mathrm{EP}=0,21, t$ $(45)=2,72, \mathrm{p}<0,05, r=0,54)$, apresentando, portanto, uma redução no tempo 3. Apesar da elevação no tempo 4 da média de PSO em relação ao tempo 3, essa diferença não foi estatisticamente significativa. Também não foram encontradas diferenças estatisticamente significativas na comparação entre as médias de PSO entre os tempos 1 e 2 .

O grupo constante apresentou um aumento na IDO, com diferenças de médias apenas entre o tempo $1(\mathrm{M}=4,55, \mathrm{EP}=0,24)$ e o tempo $3(\mathrm{M}=5,09, \mathrm{EP}=0,24, t(45)=-2,171, \mathrm{p}<$ $0,05, r=0,44)$. Apesar da redução de média acerca da IDO no tempo 4 , a diferença não foi estatisticamente significativa, quando comparada à média do tempo 4 com as demais médias. Também não foram encontradas diferenças estatisticamente significativas na comparação entre as médias de IDO entre os tempos 1 e 2, assim como entre os tempos 2 e 3.

Diante dos resultados apresentados, uma hipótese explicativa fica fortalecida: mudanças nas condições organizacionais, consideradas como não desejadas pelos atores organizacionais, REAd | Porto Alegre - Edição 76 - N 3 - setembro/dezembro 2013 - p. 675-708 
Transformações em organizações de fruticultura irrigada e a dinâmica do comprometimento organizacional

impactam de forma negativa na percepção dos trabalhadores acerca do suporte oferecido pela organização, associando-se à redução nos níveis de comprometimento, tanto afetivo quanto de continuação, e, por fim, a um aumento na intenção de deixar a organização. $O$ comprometimento se desenvolve a partir de processos de trocas, construídas entre o trabalhador, que oferece sua permanência (continuação) e afeto (afetivo), e a organização, que oferece as condições de suporte. Esse desenvolvimento ocorre, principalmente, em resposta a experiências atuais em uma organização específica. Portanto, os achados reforçam a idéia de que o contexto é um importante fator associado ao processo de comprometimento.

O presente estudo possibilita reforçar algumas conclusões da literatura da área que relacionam mudanças aos fenômenos investigados. Os achados corroboram a afirmação de Rhoades, Eisenberger e Armeli (2001) de que as condições de trabalho, que produzem a PSO, afetam o CO, assim como a conclusão de Perry (2004) de que mudanças nas normas e condições organizacionais, a exemplo do aumento de demissões e reestruturações organizacionais, fazem decrescer o $\mathrm{CO}$.

Os resultados referentes à dinâmica da PSO e do $\mathrm{CO}$, ainda que baseados em dados descritivos, reforçam a conclusão de Bishop et al. (2005) de que quando os trabalhadores percebem que a organização oferece suporte aos empregados, esses apresentam altos níveis de comprometimento. Nesse mesmo sentido, os achados também possibilitam reforçar a afirmação apresentada por inúmeros estudos (BECKER; KLEIN; MEYER, 2009; COOPERHAKIM; VISWESVARAN, 2005; MATHIEU; ZAJAC, 1990; MEYER; ALLEN, 1997; MEYER et al., 2002; VANDENBERGHE, 2009) de que quando os trabalhadores estabelecem um maior vínculo com a organização (tanto afetivo como de continuação), esses apresentam menores níveis de IDO, tanto em relação ao CA, quanto ao CC, como levantado por Meyer et al. (2002) em sua meta-análise. Análises posteriores devem avançar no sentido de buscar evidências mais robustas sobre a força e a direção das relações entre as variáveis PSO, CA, CC e IDO, o que não cabe no presente trabalho em função do recorte da questão e do objetivo do estudo. Da mesma forma, análises posteriores devem investigar as diferenças entres os dois tipos de comprometimento (afetivo e de continuação) já que a literatura aponta que estes se diferenciam nas suas relações tanto com PSO quanto com IDO. O presente relato da pesquisa, como assinalado anteriormente, concentra-se no objetivo de mostrar como variações no contexto macrossocial mostram-se relacionadas a mudanças nas variáveis do estudo, tendo-se encontrado evidências que fortalecem achados anteriores.

Os dados descritivos sugerem que as mudanças se associaram, de forma similar, tanto ao CA quanto ao CC. É importante destacar que as mudanças não foram planejadas ou mesmo

REAd | Porto Alegre - Edição 76 - N 3 - setembro/dezembro 2013 - p. 675-708 
Fabíola Marinho Costa \& Antonio Virgílio Bittencourt Bastos

desejadas, a exemplo da redução de quadro de empregados, da reestruturação de setores e do atraso nos salários. Essas mudanças podem ter sido percebidas pelos trabalhadores como violações do contrato psicológico, levando a fortes reações afetivas (ROUSSEAU, 1995), assim como podem ter causado um sentimento de falta de justiça organizacional, afetando negativamente o comprometimento organizacional (MEYER, 2009). Nesse sentido, torna-se compreensível a diminuição da identificação do trabalhador com os objetivos e valores da organização, assim como do desejo de manter-se como membro.

Essas mudanças também podem ter afetado a avaliação da relação de troca com essa organização, ou seja, impactado nas percepções sobre os custos e benefícios associados à saída da organização. Assim, a redução na tendência do trabalhador de se manter engajado na organização, ou seja, a queda do CC, pode ser justificada não apenas por uma avaliação negativa da relação de troca com essa organização, em um processo de mudanças desfavoráveis, mas, também, por características dominantes no contexto no qual está inserido esse trabalhador, como a sazonalidade das ocupações e as relações de trabalho altamente instáveis. Essas características, ainda dominantes na área rural (IPEA, 2010), podem ter interferido no processo de avaliação dos custos associados a deixar a organização, na medida em que possibilitam uma naturalização da rotatividade do trabalho, que deixa de ser percebida como um custo social, como apontado por (MONTE; PENIDO, 2008), para ser entendida como inerente à estrutura de emprego da região. Nesse sentido, a permanência na organização, em certas circunstâncias, não se constitui como uma expectativa nem para o trabalhador e nem para a organização. Os resultados apresentados, portanto, destacam que tanto o CA quanto o CC desenvolvem-se, principalmente, em resposta a experiências atuais em uma organização específica, como preconizado pela proposta teórica de Meyer e Allen (1997).

As análises dos dados, mesmo descritivas permitem corroborar a afirmação de Cohen e Freund (2005) de que o CO e a IDO são fenômenos dinâmicos. É possível, ainda, acrescentar a essa lista de fenômenos organizacionais a PSO. Apesar do reconhecimento por parte dos teóricos acerca da natureza dinâmica e processual dos fenômenos organizacionais, esta, contudo, não tem sido a perspectiva dominante no estudo do comprometimento organizacional. De acordo com Mowday, Porter e Steers (1982), o comprometimento organizacional, considerado por eles uma atitude, apresenta-se como um processo mais estável do que outros processos relacionados ao trabalho, como a satisfação. Dessa forma, o construto comprometimento, que é tratado dominantemente como uma atitude, e, logo, como algo que pode mudar, mas que não é tão fácil assim, é marcado pelas expectativas teóricas de REAd | Porto Alegre - Edição 76 - N 3 - setembro/dezembro 2013 - p. 675-708 
Transformações em organizações de fruticultura irrigada e a dinâmica do comprometimento organizacional

que seja um fenômeno relativamente estável e mais duradouro através do tempo, possibilitando tratá-lo como um construto estático. Os resultados da presente pesquisa, entretanto, sugerem uma compreensão mais dinâmica e processual do construto, na medida em que reforçam o argumento de que os vínculos de compromisso não ficam imunes à perda de suporte organizacional, em função de mudanças organizacionais relacionadas a situações de crise.

A presente investigação também apresenta indícios de que mudanças em um nível macro (relativo ao contexto internacional e mais amplo, marcado por uma crise econômica mundial) podem impactar o funcionamento organizacional (com demissões, reestruturações e atrasos de salários) e, por conseguinte, afetar o nível micro (relacionado às atitudes dos trabalhadores). Como exposto por Fajardo (2008), é possível observar a imposição de uma lógica global de produção, circulação e consumo que direciona as atividades agrícolas. Essa lógica implica a dependência da economia da região de fruticultura irrigada do Vale do São Francisco em relação à exportação para alguns países, em especial os Estados Unidos da América. Alterações nessa dinâmica produtiva geral, como a queda da demanda do consumo no mercado externo, resultam em um impacto direto com consequências imediatas, que podem abranger inclusive o estabelecimento de vínculos entre trabalhadores e organizações agrícolas. Essa conclusão reforça o argumento de Beck e Wilson (2001) de que o comprometimento e o contexto no qual ele existe são interdependentes, reafirmando a necessidade de buscar uma compreensão mais acurada dos contextos organizacionais e macro sociais em mudança quando considerados fenômenos organizacionais, a exemplo de PSO, CO e IDO.

\section{CONSIDERAÇÕES FINAIS}

O presente trabalho avaliou, ao longo de dois anos, o processo de comprometimento organizacional afetivo, de comprometimento organizacional de continuação, de percepção de suporte organizacional e de intenção de deixar a organização entre trabalhadores de organizações agrícolas em um contexto de transformações. Seu objetivo central foi o de explorar possíveis relações entre mudanças no contexto econômico e social em que a organizações estão imersas e mudanças nos processos psicossociais intraorganizacionais que afetam o comprometimento do trabalhador e a sua intenção de permanecer na organização.

Os achados apresentados reforçam uma perspectiva processual do comprometimento organizacional, fortalecendo a hipótese explicativa de que mudanças nas condições organizacionais, consideradas como não desejadas pelos atores organizacionais, impactam de

REAd | Porto Alegre - Edição 76 - N 3 - setembro/dezembro 2013 - p. 675-708 
Fabíola Marinho Costa \& Antonio Virgílio Bittencourt Bastos

forma negativa na percepção dos trabalhadores acerca do suporte oferecido pela organização, associando-se à redução nos níveis de comprometimento, tanto afetivo quanto de continuação, e, por fim, a um aumento na intenção de deixar a organização. Os resultados sugerem que esses processos, ainda que tratem dos vínculos dos indivíduos, por serem similares entre o grupo total de cada tempo e o grupo constante dos 46 trabalhadores, podem ser considerados como processos coletivos, tomando a organização como unidade de análise.

Ao longo do tempo, foram identificadas mudanças que apontam para um enfraquecimento dos vínculos, assim como indicados possíveis fatores contextuais associados a essas mudanças, fortalecendo a ideia de que transformações organizacionais decorrentes de ajustes a demandas postas por uma crise de âmbito internacional se constituem como um potencial redutor do comprometimento dos trabalhadores, pela redução do suporte que era oferecido pela organização a seus empregados. Diante disso, torna-se importante que estudiosos e profissionais da área do Comportamento Organizacional estejam atentos aos eventos ambientais, haja vista os possíveis impactos desses em diferentes processos psicossociais. Da mesma forma, é importante que gestores se tornem atentos à forma como os ajustes organizacionais ao ambiente impactam processos micro-organizacionais que, ao afetarem os vínculos do trabalhador com a organização, podem dificultar a retomada dos indicadores de desempenho, individual e coletivo, quando passada a turbulência externa. Além da redução do quadro de pessoal, da diminuição da atividade produtiva, o gestor passou a lidar com um grupo de trabalhadores menos comprometidos e mais dispostos a deixar a organização em existindo alguma alternativa.

Ainda que adotando uma abordagem longitudinal, o presente estudo encontra-se distante do entendimento de uma compreensão integral de como processos individuais e organizacionais se articulam e se constroem no cotidiano, ao longo do tempo. Nesse sentido, aponta-se a necessidade de mais estudos sobre a mudança nos vínculos estabelecidos entre trabalhador e organização, com o intuito de compreender como esses se desenvolvem e identificar fatores relacionados ao desenvolvimento. Ressalta-se que o reconhecimento da relevância de fatores contextuais (organizacionais e sociais), apoiado por uma abordagem macro-orientada, não deve excluir explorações micro-orientadas, a partir de uma perspectiva mais individual, que considera variáveis disposicionais (traços, personalidade e atitudes).

Avaliar impactos de mudanças em um nível contextual sobre um fenômeno que ocorre no nível individual requereu, no presente estudo, o uso de método qualitativo (para monitorar as mudanças ambientais, especialmente percebidas pelo gestor) e um desenho longitudinal para captar alterações no fenômeno quantitativamente avaliado. O uso de múltiplos métodos

REAd | Porto Alegre - Edição 76 - N 3 - setembro/dezembro 2013 - p. 675-708 
Transformações em organizações de fruticultura irrigada e a dinâmica do comprometimento organizacional

aliado às dificuldades das pesquisas em contextos organizacionais, especialmente no segmento do agronegócio com seu elevado índice de rotatividade, dificultou o emprego de técnicas estatísticas multivariadas mais complexas que adicionariam mais evidências do nexo causal encontrado entre crise internacional, mudança nas políticas de pessoal das empresas, diminuição da percepção de suporte organizacional, queda do comprometimento e aumento da intenção de deixar a organização. O estudo aqui relatado, ao combinar, em um desenho longitudinal, dados qualitativos e quantitativos, mesmo analisados descritivamente, oferece forte suporte empírico para um pressuposto largamente aceito entre pesquisadores, mas praticamente não investigado na área - o de que o comprometimento é um fenômeno multideterminado que inclui fatores contextuais que estão para além dos limites da própria organização.

Enfim, reafirma-se a importância do desenvolvimento de modelos teóricos que expliquem a dinâmica do comprometimento organizacional, assim como da aplicação dos conhecimentos, academicamente produzidos, por meio da fundamentação de políticas e práticas organizacionais.

\section{REFERÊNCIAS}

ALLEN, N. J.; MEYER, J. P. The measurement and antecedents of affective, continuance, and normative commitment to the organization. Journal of Occupational Psychology, v. 63, p. $1-18,1990$.

BASTOS, A. V. B. Comprometimento organizacional: a estrutura dos vínculos do trabalhador com a organização, a carreira e o sindicato. 1994. 293 f. Tese (Doutorado em Psicologia) - Instituto de Psicologia, Universidade de Brasília, Brasília, 1994.

BECKER, T. E.; KLEIN, H. J.; MEYER, J. P. Commitment in organizations: accumulated wisdom and new directions. In: . (Org.). Commitment in Organizations. Accumulated Wisdom and New Directions. New York / London: Routledge - Taylor \& Francis Group, 2009. p. 419-452.

BECK, K.; WILSON, C. Have we studied, should we study, and can we study the development of commitment? Methodological issues and the developmental study of workrelated commitment. Human Resource Management Review, v. 11, p. 257-278, 2001.

BENTEIN, K. et al. The role of change in the relationship between commitment and turnover: a latent growth modeling approach. Journal of Applied Psychology, v. 90, n. 3, p. 468-482, 2005. 
Fabíola Marinho Costa \& Antonio Virgílio Bittencourt Bastos

BISHOP, J. W. et al. A construct validity study of commitment and perceived support variables: a multifoci approach across different team environments. Group \& Organization Management, v. 30, n. 2, p. 153-180, 2005.

BORGES-ANDRADE, J. E.; AFANASIEF, R. S.; SILVA, M. S. Mensuração de comprometimento organizacional em instituições públicas. In: REUNIÃO ANUAL DE PSICOLOGIA, 19, 1989, Ribeirão Preto. Anais... Ribeirão Preto: Sociedade de Psicologia de Ribeirão Preto, 1989. p. 236.

BOSWELL, W. R. et al. Second-class citizen? Contract workers' perceived status, dual commitment and intent to quit. Journal of Vocational Behavior, v. 80, p. 454-463, 2012.

CASPER, W. J. et al. Work-family conflict, perceived supervisor support and organizational commitment among Brazilian professional. Journal of Vocational Behavior, v. 79, p. 640$652,2011$.

CAVALCANTI, J. S. B.; MOTA, D. M.; SILVA, P. C. G. Transformações recentes nos espaços de fruticultura do Nordeste do Brasil. In: ELIAS, D.; PEQUENO, R. (Org.). Difusão do agronegócio e novas dinâmicas socioespaciais. Fortaleza: Banco do Nordeste do Brasil, 2006. p. 117-149.

CHANG, H.-T.; CHI, N.-W.; MIAO, M.-C. Testing the relationship between threecomponent organizational/occupational commitment and organizational/occupational turnover intention using a non-recursive model. Journal of Vocational Behavior, v. 70, p. 352-368, 2007.

COHEN, A. Commitment before and after: an evaluation and reconceptualization of organizational commitment. Human Resource Management Review, v. 17, p. 336-354, 2007a.

. Dynamics between occupational and organizational commitment in the context of flexible labor markets: a review of the literature and suggestions for a future research agenda. Institut Technik und Bildung (ITB), Universität Bremen, 2007b. 22 p.

COHEN, A.; FREUND, A. A longitudinal analysis of the relationship between multiple commitments and withdrawal cognitions. Scandinavian Journal of Management, v. 21, p. 329-351, 2005.

COLLINS, L. M. Analysis of longitudinal data: the integration of theoretical model, temporal design, and statistical model. Annual Review of Psychology, v. 57, p. 505-528, 2006. 
Transformações em organizações de fruticultura irrigada e a dinâmica do comprometimento organizacional

COOPER-HAKIM, A.; VISWESVARAN, C. The construct of work commitment: testing an integrative framework. Psychological Bulletin, v. 131, n 2, p. 241-259, 2005.

CORREIA, R. C.; ARAÚJO, J. L. P.; CAVALCANTI, E. B. A fruticultura como vetor de desenvolvimento: o caso dos municípios de Petrolina (PE) e Juazeiro (BA). In: CONGRESSO BRASILEIRO DE ECONOMIA E SOCIOLOGIA RURAL, 39, 2001, Recife, PE. Anais... Recife: SOBER/ESALQ/EMBRAPA/UFPE/URFPE, 2001. 1 CD.

COSTA, F. M. Múltiplos comprometimentos no trabalho: identificando padrões e explorando antecedentes entre trabalhadores de organizações agrícolas. 2005. 179 f. Dissertação (Mestrado em Psicologia) - Faculdade de Filosofia e Ciências Humanas, Universidade Federal da Bahia, Bahia, 2005.

COSTA, F. M.; BASTOS, A. V. V. Múltiplos comprometimentos no trabalho: um estudo entre trabalhadores de organizações agrícolas do pólo de fruticultura irrigada de Juazeiro/Petrolina. Revista de Administração da UFSM, v. 2, n. 2, p. 280-297, 2009.

COSTA, V. M. F. As bases afetiva e instrumental do comprometimento organizacional: confrontando suas diferenças entre empresas da fruticultura irrigada do Pólo Juazeiro Petrolina. 2007. 269 f. Tese (Doutorado em Administração) - Faculdade de Administração, Universidade Federal da Bahia, Bahia. 2007.

CULPEPPER, R.A. Three-component commitment and turnover: an examination of temporal aspects. Journal of Vocational Behavior, v. 79, p. 517-527, 2011.

DULCI, O. S. Economia e política na crise global. Estudos Avançados, v. 23, n. 65, p. 105$119,2009$.

EISENBERGER, R. et al. Perceived organizational support. Journal of Applied Psychology, v. 71, p. 500-507, 1986.

FAJARDO, S. Complexo agroindustrial, modernização da agricultura e participação das cooperativas agropecuárias no estado do Paraná. Caminhos de Geografia, v. 9, n. 27, p. 3144, 2008.

FELFE, J.; YAN, W.; SIX, B. The impact of individual collectivism on commitment and its influence on organizational citizenship behaviour and turnover in three countries. International Journal of Cross Cultural Management, v. 8, n. 2, p. 211-237, 2008.

GUIMARÃES, T. G. Visita técnica ao pólo frutícola do Vale do São Francisco, em Petrolina, PE e Juazeiro, BA. Planaltina, DF: Embrapa Cerrados, 2007. 34 p.

REAd | Porto Alegre - Edição 76 - N 3 - setembro/dezembro 2013 - p. 675-708 
Fabíola Marinho Costa \& Antonio Virgílio Bittencourt Bastos

INSTITUTO BRASILEIRO DE GEOGRAFIA E ESTATÍSTICA, COORDENAÇÃO DE GEOGRAFIA. Vetores estruturantes da dimensão socioeconômica da Bacia Hidrográfica do Rio São Francisco: 2009. Rio de Janeiro: IBGE, 2009. 179 p.

INSTITUTO DE PESQUISA ECONÔMICA APLICADA [IPEA]. A crise internacional e possíveis repercussões: primeiras análises. Comunicado da Presidência, v. 16, 2009a. 16 p.

[IPEA]. A necessidade de uma nova política

de comercialização agrícola. Texto para Discussão, v. 1440, 2009b, 20 p.

[IPEA]. PNAD 2008: Primeiras análises - o

setor rural, v. 42, 2010, 23 p.

KLEIN, H. J.; MOLLOY, J. C.; COOPER, J. T. Conceptual foundations: construct definitions and theoretical representations of workplace commitments. In: BECKER, T. E.; KLEIN, H. J.; MEYER, J. P. (Org.). Commitment in Organizations. Accumulated Wisdom and New Directions. New York / London: Routledge - Taylor \& Francis Group, 2009. p. 3-36.

KONDRATUK, T. B. et al. Linking career mobility with corporate loyalty: How does job change relate to organizational commitment? Journal of Vocational Behavior, v. 65, p. 332349, 2004.

LEE, J.; CORBETT, J. M. The impact of downsizing on employees' affective commitment. Journal of Managerial Psychology, v. 21, n. 3, p. 176-199, 2006.

MATHIEU, J. E.; ZAJAC, D. M. A Review and Meta-Analysis of the Antecedents, Correlates, and Consequences of Organizational Commitment. Psychological Bulletin, v. 108 n. 2, p. 171-194, 1990.

MEDEIROS, C. A. F.; ENDERS, W. T. Validação do modelo de conceitualização de três componentes do comprometimento organizacional de Meyer e Allen. Revista de Administração Contemporânea, v. 2, n. 3, p. 67-87, 1998.

MEYER, J. P. Commitment in a changing world of work. In: BECKER, T. E.; KLEIN, H. J.; MEYER, J. P. (Org.). Commitment in Organizations. Accumulated Wisdom and New Directions. New York / London: Routledge - Taylor \& Francis Group, 2009. p. 37-68.

MEYER, J. P.; ALLEN, N. J. Testing the "side-bet theory" of commitment: some methodological consideratios. Journal of Applied Psychology, v. 69, p. 372-378, 1984. 
Transformações em organizações de fruticultura irrigada e a dinâmica do comprometimento organizacional

Commitment in the workplace: theory, research and

application. Thousands Oaks, SAGE, 1997. 149 p.

MEYER, J. P. et al. Affective, Continuance, and Normative Commitment to the Organization: A Meta-analysis of Antecedents, Correlates, and Consequences. Journal of Vocational Behavior, v. 61, p. 20-52, 2002.

MONTE, P. A.; PENIDO, M. R. J. Determinantes da duração esperada do emprego urbano e rural no Nordeste brasileiro. Revista de Economia e Sociologia Rural, v. 46, n. 04, p. 9891014, 2008.

MORROW, P.C. Managing organizational commitment: Insights from longitudinal research. Journal of Vocational Behavior, v. 79, p. 18-35, 2011.

MOWDAY, R. T.; PORTER, L. W.; STEERS, R. M. Employee-organization linkages: the psychology of commitment, absenteeism, and turnover. New York: Academic Press, 1982. $253 \mathrm{p}$.

MOWDAY, R. T.; STEERS, R. M.; PORTER, L. W. The measurement of organizational commitment. Journal of Vocational Behavior, v. 14, p. 224-247, 1979.

NEININGER, A. et al. Effects of team and organizational commitment - A longitudinal study. Journal of Vocational Behavior, v. 76, p. 567-579, 2010.

NORD, W. R.; FOX, S. O indivíduo nos estudos organizacionais: o grande ato de desaparecimento? In: S. R. CLEGG, C. HARDY E W. NORD (Org.). Handbook de Estudos Organizacionais. São Paulo: Atlas, 2004.

OLIVEIRA, J. E. M. et al. Produção integrada de uva no Vale do São Francisco. In: XX CONGRESSO BRASILEIRO DE FRUTICULTURA, 54TH ANNUAL MEETING OF THE INTERAMERICAN SOCIETY FOR TROPICAL HORTICULTURE, 2008, Vitória, ES. Anais... Vitória, 2008.

OLIVEIRA, A. M. B.; RIGO, A. S.; CARVALHO, D. M. Financiamento e gerenciamento de capital de giro em empresas de fruticultura irrigada: um estudo de caso no Vale do São Francisco. Revista Eletrônica de Gestão, v. 2, n. 2, p. 7-24, 2009.

PARÉ, G.; TREMBLAY, M. The influence of high-involvement human resources practices, procedural justice, organizational commitment, and citizenship behaviors on information technology professionals' turnover intentions. Group \& Organization Management, v. 32, n. 3, p. 326-357, 2007.

REAd | Porto Alegre - Edição 76 - N 3 - setembro/dezembro 2013 - p. 675-708 
Fabíola Marinho Costa \& Antonio Virgílio Bittencourt Bastos

PERRY, R.W. The relationship of affective organizational commitment with supervisory trust. Review of Public Personnel Administration, v. 24, n. 2, p. 133-149, 2004.

RHOADES, L.; EISENBERGER, R.; ARMELI, S. Affective commitment to the organization: the contribution of perceived organizational support. Journal of Applied Psychology, v. 86, n. 5, p. 825-836, 2001.

ROUSSEAU, D. M. Psychological contract in organizations: understanding written and unwritten agreements. Thousand Oaks, CA: Sage, London, 1995. 235 p.

SUPERINTENDÊNCIA DE ESTUDOS ECONÔMICOS E SOCIAIS DA BAHIA [SEI]. Recentes transformações no rural baiano. Salvador, 2003. 70 p. (Série Estudos e Pesquisas, n. 68)

SILVA, P. C. G. Articulação dos interesses públicos e privados no pólo PetrolinaPE/Juazeiro-BA: em busca de espaço no mercado globalizado de frutas frescas. 2001. $245 \mathrm{f}$. Tese (Doutorado em Economia) - Instituto de Economia, Universidade Estadual de Campinas, Campinas. 2001.

SIQUEIRA, M. M. M. Antecedentes de comportamentos de cidadania organizacional: a análise de um modelo pós-cognitivo. 1995. 265 f. Tese (Doutorado em Psicologia) - Instituto de Psicologia, Universidade de Brasília, Brasília. 1995.

Esquema mental de reciprocidade e influências sobre afetividade no trabalho. Estudos de Psicologia, v. 10, n. 1, p. 83-93, 2005.

VANDENBERGHE, C. Organizational Commitments. In: BECKER, T. E.; KLEIN, H. J.; MEYER, J. P. (Org.). Commitment in Organizations. Accumulated Wisdom and New Directions. New York / London: Routledge - Taylor \& Francis Group, 2009. p. 99-135.

VANDENBERGHE, C.; BENTEIN, K.; STINGLHAMBER, F. Affective commitment to the organization, supervisor, and work group: Antecedents and outcomes. Journal of Vocational Behavior, v. 64, p. 47-71, 2004.

VANDENBERGHE, C. et al. An examination of the role of perceived support and employee commitment in employee-customer encounters. Journal of Applied Psychology, v. 92, n. 4, p. 1177-1187, 2007.

WAYNE, S. J. et al. Social influences. In: BECKER, T. E.; KLEIN, H. J.; MEYER, J. P. (Org.). Commitment in Organizations. Accumulated Wisdom and New Directions. New York I London: Routledge - Taylor \& Francis Group, 2009. p. 253-284.

REAd | Porto Alegre - Edição 76 - N 3 - setembro/dezembro 2013 - p. 675-708 
Transformações em organizações de fruticultura irrigada e a dinâmica do comprometimento organizacional

WRIGHT, P. M.; KEHOE, R. R. Organizational-Level Antecedents and Consequences of Commitment. In: BECKER, T. E.; KLEIN, H. J.; MEYER, J. P. (Org.), Commitment in Organizations. Accumulated Wisdom and New Directions. New York / London: Routledge Taylor \& Francis Group, 2009. p. 285-307.

ZAGENCZYK, T. J. et al. Social influence and perceived organizational support: A social networks analysis. Journal of Vocational Behavior, v. 111, p. 127-138, 2010. 